BMJ Open

Diabetes

Research

\& Care

\title{
Factors associated with undiagnosed type 2 diabetes in Germany: results from German Health Interview and Examination Survey for Adults 2008-2011
}

\author{
Yong Du (D) , ${ }^{1}$ Jens Baumert (10 , ${ }^{1}$ Rebecca Paprott, ${ }^{1}$ Andrea Teti (D) , ${ }^{1,2}$ \\ Christin Heidemann (D) , ${ }^{1}$ Christa Scheidt-Nave ${ }^{1}$
}

To cite: Du Y, Baumert J, Paprott R, et al. Factors associated with undiagnosed type 2 diabetes in Germany: results from German Health Interview and Examination Survey for Adults 2008-2011. BMJ Open Diab Res Care 2020;8:e001707. doi:10.1136/ bmjdrc-2020-001707

- Supplemental material is published online only. To view, please visit the journal online (http://dx.doi.org/10.1136/ bmjdrc-2020-001707).

Received 19 June 2020 Revised 1 September 2020 Accepted 5 September 2020

Check for updates

C) Author(s) (or their employer(s)) 2020. Re-use permitted under CC BY-NC. No commercial re-use. See rights and permissions. Published by BMJ.

${ }^{1}$ Department of Epidemiology and Health Monitoring, Robert Koch Institute, Berlin, Germany ${ }^{2}$ Institute for Gerontology, University of Vechta, Vechta, Lower Saxony, Germany

Correspondence to Dr Christa Scheidt-Nave; Scheidt-NaveC@rki.de

\section{ABSTRACT}

Introduction To identify characteristics of people with undiagnosed type 2 diabetes (T2D) among adults in Germany.

Research design and methods The study population comprised participants aged 40-79 years of the German Health Interview and Examination Survey for Adults 2008-2011. Glycemic status was categorized as undiagnosed T2D (glycated hemoglobin A1C (HbA1c) $\geq 48 \mathrm{mmol} / \mathrm{mol}(6.5 \%), \mathrm{n}=135)$, diagnosed T2D $(\mathrm{n}=518)$ and normoglycemia $(\mathrm{HbA} 1 \mathrm{c}<48 \mathrm{mmol} /$ $\mathrm{mol}(6.5 \%), \mathrm{n}=4451)$. Multinomial logistic regression models including glycemic status as the outcome variable and sociodemographic characteristics, living alone, diabetes risk factors and healthcare services utilization as independent variables were used to identify factors associated with undiagnosed T2D compared with normoglycemia and diagnosed T2D. Odds ratios (ORs) and 95\% confidence intervals (Cls) are reported as measure of association between the outcome and independent variables.

Results The prevalence of undiagnosed T2D was $2.9 \%$ $(95 \% \mathrm{Cl} 2.2 \%$ to $3.9 \%)$ at an overall prevalence of $12.3 \%(11.0 \%$ to $13.6 \%)$ of persons with undiagnosed or diagnosed T2D. In multivariable analyses, factors associated with undiagnosed as well as diagnosed T2D in comparison to normoglycemia were older age (OR 1.04, $95 \% \mathrm{Cl} 1.01$ to 1.06 , per year, for undiagnosed T2D; OR 1.08, 1.07 to 1.10 for diagnosed T2D), male sex (3.33, 2.18 to $5.07 ; 1.91,1.43$ to 2.56$)$, obesity $(3.47,2.17$ to 5.56 ; $2.68,2.04$ to 3.52$)$, hypertension $(1.66,1.09$ to 2.53 ; $2.04,1.42$ to 2.95$)$ and parental history of diabetes (2.04, 1.24 to $3.35 ; 3.16,2.30$ to 4.34$)$. Variables independently associated with undiagnosed T2D but not diagnosed T2D included living alone $(2.20 ; 1.36$ to 3.56$)$ and not seeing a doctor within the past year $(2.57 ; 1.34$ to 4.93$)$. People with undiagnosed T2D were further younger and more likely to be male sex and reside in the western part of Germany than people with diagnosed T2D.

Conclusion Apart from major known risk factors of diabetes, characteristics specific to undiagnosed diabetes among adults in Germany will serve to inform the national education and communication strategy on diabetes mellitus in Germany.

\section{Significance of this study}

What is already known about this subject?

- Undiagnosed diabetes still remains a problem even in high-income countries with universal access to healthcare.

- Identifying characteristics specific to undiagnosed diabetes is necessary to improve diabetes-related risk communication and quality of care.

What are the new findings?

- Apart from major known risk factors of diabetes, male sex, younger age, residing in the western part of Germany, living alone and not regularly seeing a doctor were characteristics of people with undiagnosed type 2 diabetes (T2D) versus diagnosed T2D in Germany.

How might these results change the focus of research or clinical practice?

- Our results will serve to inform national education and communication strategy on diabetes mellitus in Germany, which is currently developed by the German Federal Center for Health Education.

\section{INTRODUCTION}

Type 2 diabetes (T2D) is a chronic metabolic disease characterized by an elevated level of blood glucose. Microvascular and macrovascular complications of T2D such as retinopathy, nephropathy, neuropathy-which may lead to blindness, renal failure and amputation-and cardiovascular diseases (CVD) exert a high financial burden for people with diabetes and for the health system. The progression of T2D is slow and may last several years before diagnosis. In the early stage of T2D, people with T2D may not show any symptoms and therefore not be detected and not get treated, whereas microvascular and macrovascular complications may have 
already developed during this stage. ${ }^{12}$ It is estimated that $13 \%$ of adults with T2D have diabetic retinopathy at the time of diagnosis and many of them have CVD. ${ }^{34}$ Undiagnosed T2D bears a high risk for long-term microvascular and macrovascular complications and for a higher mortality compared with normoglycemic individuals. ${ }^{56}$ Identification of undiagnosed T2D at an early stage is thus of importance for a timely care.

While general screening for undiagnosed T2D among asymptomatic individuals may well reduce CVD and mortality risk among those who are detected by screening, ${ }^{78}$ benefits at the population level regarding a reduction in mortality or cardiovascular event rates are less clear. ${ }^{9}$ Case finding strategies or opportunistic screening within the healthcare settings has been proposed to be more efficient. ${ }^{10}$ As these strategies will not reach individuals at high risk who do not regularly use healthcare services, risk communication to the public is also a crucial part of a national diabetes strategy. Identifying characteristics related to undiagnosed diabetes would be valuable to both, case finding and risk communication strategies.

Undiagnosed diabetes remains a problem even in highincome countries with universal access to healthcare. ${ }^{11} 12$ In Germany, $2 \%$ of the adult population 18-79 years of age were estimated to have undiagnosed diabetes based on laboratory testing for glycated hemoglobin A1c (HbAlc) as part of the German Health Interview and Examination Survey 2008-2011 (DEGS1). ${ }^{13}$ Undiagnosed diabetes accounted for about $22 \%$ of total diabetes. ${ }^{13}$ In stratified analyses, both diagnosed as well as undiagnosed diabetes were more prevalent among men than women, older adults, those with obesity and those with low education. ${ }^{13}$ However, correlates specific to undiagnosed diabetes in Germany have not been systematically investigated so far. Correlates and predictors of undiagnosed diabetes have been previously investigated in several other high-income countries such as the USA, ${ }^{14-16}$ the UK, ${ }^{17}{ }^{18}$ Denmark, ${ }^{19}$ Ireland, ${ }^{20}{ }^{21}$ South Korea ${ }^{22}$ as well as in some low-income countries. ${ }^{23-27}$ Results of previous studies from highincome countries vary, which may be explained, at least in part, by differences in study design, characteristics of the study population as well as health system factors. ${ }^{14-22}$ There is evidence, however, from some studies that personal context factors, such as healthcare utilization behavior and marital or cohabitation status are factors associated with undiagnosed diabetes. ${ }^{28}$

Against this background, the present study aimed to identify clinical, sociodemographic and behavioral characteristics of adults with undiagnosed diabetes in Germany. We specifically sought to identify factors correlated with undiagnosed but not diagnosed diabetes.

\section{RESEARCH DESIGN AND METHODS}

Study design and participants

The German Health Interview and Examination Survey for Adults was conducted by the Robert Koch Institute from November 2008 to December 2011 as part of the continuous national health monitoring. The two-stage random cluster design and specific aims of this national health survey have been previously described in detail. ${ }^{29}$ The response rate was $62 \%$ for re-participants and $42 \%$ for newly recruited participants. ${ }^{29}$

In DEGS1, a total of 7115 adults aged 18-79 years completed the interview and examination components. ${ }^{29}$ To focus on T2D, we excluded individuals who were likely to have type 1 diabetes (T1D) $(\mathrm{n}=8)$ and women likely to have had gestational diabetes $(n=42)$ according to previously defined criteria. ${ }^{30}$ As T2D occurs mainly among people over 40 years of age, we further excluded people $<40$ years of age $(n=1887)$ along with individuals with missing information on diabetes diagnosis $(n=30)$ or HbA1c values $(n=44)$. Thus, the final study population comprised 5104 adults aged $40-79$ years.

\section{Data collection}

Data collection in DEGS1 included self-administered questionnaires, computer-assisted personal interviews (CAPI) administered by study physicians to obtain a detailed medical history, laboratory tests and anthropometric measurements including serum lipids, HbAlc, blood pressure and body weight and height for the calculation of body mass index (BMI) ${ }^{29}$ We conducted a computer-assisted brown bag review of all medications used in the past 7 days. Universal product codes on the original medication containers were scanned and coded according to the WHO Anatomical Therapeutic Chemical (ATC) classification system. ${ }^{29}$

\section{Dependent variable}

Undiagnosed T2D as the main outcome variable was defined if survey participants answered 'no' to the CAPI question "Have you ever been diagnosed with diabetes by a doctor?" and were not taking antidiabetic medications (ATC code A10), but had HbA1c measures $\geq 48 \mathrm{mmol} /$ mol $(\geq 6.5 \%)$. Study participants fulfilled criteria for diagnosed T2D if they reported that they had ever been diagnosed with diabetes by a physician or if they were currently taking antidiabetic medications. Survey participants without a medical history of diabetes or current medication use and $\mathrm{HbAlc}$ measures $<48 \mathrm{mmol} / \mathrm{mol}$ $(<6.5 \%)$ were categorized as normoglycemic. ${ }^{13}$

\section{Independent variables}

We identified potential factors associated with undiagnosed diabetes based on a non-systematic review of the medical literature on population-based studies of predictors or factors associated with undiagnosed diabetes. Based on information collected in DEGS1, we selected the following independent variables for analysis in the present study: sociodemographic characteristics (age, community size, residence in the western or eastern part of Germany, cohabitation status, educational attainment), known risk factors for T2D (smoking, sports activity and alcohol consumption, obesity, hypertension 
and hyperlipidemia, family history of diabetes), depressive symptoms, and ambulatory care utilization in the past year.

As previously described in detail, we applied Comparative Analysis of Social Mobility in Industrial Nations (CASMIN) criteria ${ }^{31}$ to define educational status as low (CASMIN 1: primary and low secondary education), middle (CASMIN 2: intermediate/high secondary education) or high (CASMIN 3: tertiary education). ${ }^{13} 32$ For analysis, we dichotomized education status into low versus middle or high due to small numbers of adults with a high education level, in particular among older women. We dichotomized community size into large/ middle cities versus rural areas/small cities and regions of residence into West versus East Germany based on standardized classification criteria. ${ }^{13} 32$ Cohabitation status was grouped into living alone or together with at least one person in the same household. Current smoking and sports activity were dichotomized as yes/ no based on self-reported information. ${ }^{32}$ Alcohol use was grouped into three categories none, moderate and risky drinking based on information obtained with food frequency questionnaires. ${ }^{33}$ Obesity was defined based on BMI measures $\geq 30 \mathrm{~kg} / \mathrm{m}^{2} .{ }^{132}$ Hyperlipidemia was defined as total cholesterol $\geq 6.2 \mathrm{mmol} / \mathrm{L}$ or current use of lipid-lowering drugs (ATC code C10) in combination with a medical history of hyperlipidemia. Hypertension was defined as systolic blood pressure $\geq 140 \mathrm{~mm} \mathrm{Hg}$ (18.7 $\mathrm{kPa}$ ) or diastolic blood pressure $\geq 90 \mathrm{~mm} \mathrm{Hg}(12.0 \mathrm{kPa})$ or current use of antihypertensive drugs in combination with a medical history of hypertension. ${ }^{34}$ A family history of diabetes was defined based on information that the father or mother had ever been diagnosed with diabetes. Persons with depressive symptoms measured by the 9-item depression module of the Patient Health Questionnaire (PHQ-9) were defined as those with a PHQ-9 score $\geq 10 .{ }^{33}$ Regular primary care utilization was defined as having seen a doctor in office practice (excluding dentists) at least once within the preceding 12 months.

\section{Statistical analysis}

All statistical analyses were performed using Stata (V.15.0, StataCorp, College Station, Texas, USA). A weighting factor was used to adjust for deviations in demographic characteristics between the study population and official population statistics of 31 December $2010 .^{29}$

Descriptive statistics were used to assess the distribution of independent variables in the entire study population and among subgroups of people with undiagnosed T2D, diagnosed T2D and normoglycemia. We report point prevalence estimates and 95\% confidence intervals (CIs) for categorical variables, means and $95 \%$ CIs for continuous variables, along with absolute numbers of observations and absolute numbers of missing observations for each variable.

In order to identify similarities and differences in factors associated with undiagnosed and diagnosed T2D, we used multinomial logistic regression analyses (Stata command mlogit). Glycemic status with three categories (undiagnosed T2D, diagnosed T2D, normoglycemia) was the dependent variable using normoglycemia as the reference group in the first set of analyses. This permitted identification of factors significantly associated with both diagnosed and undiagnosed T2D versus normoglycemia. Independent variables selected as potential factors associated with undiagnosed or diagnosed T2D were consecutively entered into the regression model in four steps, starting with basic sociodemographics including age as a continuous variable, sex and education (model 1), adding information on community size, region of residence and cohabitation status (model 2), further adding behavioral cardiometabolic risk factors (model 3) and finally also adding information on cardiometabolic comorbidities, depressive symptoms and ambulatory healthcare utilization (model 4). We then repeated the multinomial logistic regression analyses as described above using diagnosed T2D as reference group. This enabled us to identify those factors which were associated with undiagnosed T2D in comparison to diagnosed T2D. We obtained relative risk ratios and 95\% CIs from Stata multinomial logistic regression models, which can be interpreted as odds ratios (ORs). ${ }^{35}$ In the present study, results from multinomial logistic regression analyses are therefore reported as ORs and 95\% CIs as a measure of the association between independent and outcome variables.

Overall, $15.9 \%$ of participants had a missing value in at least one variable and proportions of missing observations in independent variables ranged from $0.2 \%$ for hypertension to $7.9 \%$ for parental history of diabetes. We applied 15 multiple imputations by chained equations assuming an arbitrary pattern of missingness for missing values. Multinomial logistic regression models were performed for these 15 imputed datasets and estimates were then combined according to Rubin's rules taking into account variability within and between the imputations. ${ }^{36}$ Sex differences in the associations were tested by adding first order interaction terms to the final model. Complete case analyses ( $\mathrm{n}=4295$ or $84.1 \%$ of study population) were conducted as sensitivity analyses. A p value $<0.05$ was considered as statistically significant based on two-sided tests.

\section{RESULTS}

Descriptive characteristics of the study population are summarized in table 1 . Among adults aged 40-79 years included in the present study, 135 individuals fulfilled the criteria for undiagnosed T2D, and 518 individuals had diagnosed T2D. The weighted prevalence of undiagnosed T2D was $2.9 \%$ (95\% CI 2.2\% to $3.9 \%$ ) (table 1 ). The prevalence of total diabetes was $12.3 \%$ (95\% CI $11.0 \%$ to $13.6 \%$ ), and undiagnosed T2D accounted for about one-quarter of total diabetes cases.

The mean age of the study population was $57.0(95 \%$ CI 56.7 to 57.4) years. The vast majority of study participants resided in the western part of Germany and about 
Table 1 Descriptive characteristics of study subjects aged $40-79$ years $(n=5104)$. German Health Interview and Examination Survey for Adults 2008-2011 (DEGS1)

\begin{tabular}{|c|c|c|c|}
\hline & $\mathbf{N}$ & $\%$ * & $95 \% \mathrm{Cl}^{*}$ \\
\hline \multicolumn{4}{|l|}{ Glycemic status } \\
\hline Undiagnosed diabetes & 135 & 2.9 & 2.2 to 3.9 \\
\hline Diagnosed diabetes & 518 & 9.3 & 8.4 to 10.4 \\
\hline Normoglycemia & 4451 & 87.7 & 86.4 to 89.0 \\
\hline \multicolumn{4}{|l|}{ Sex } \\
\hline Men & 2441 & 49.4 & 47.7 to 51.1 \\
\hline Women & 2663 & 50.6 & 48.9 to 52.3 \\
\hline \multicolumn{4}{|l|}{ Age group, years } \\
\hline $40-49$ & 1265 & 32.2 & 30.8 to 33.7 \\
\hline $50-59$ & 1375 & 27.4 & 26.2 to 28.7 \\
\hline $60-69$ & 1371 & 21.1 & 20.0 to 22.4 \\
\hline $70-79$ & 1093 & 19.2 & 18.2 to 20.3 \\
\hline \multicolumn{4}{|l|}{ Community } \\
\hline Rural area/small cities & 2178 & 41.7 & 34.1 to 49.8 \\
\hline Middle/Large cities & 2926 & 58.3 & 50.2 to 65.9 \\
\hline \multicolumn{4}{|l|}{ Region } \\
\hline West Germany & 3434 & 78.4 & 72.0 to 83.7 \\
\hline East Germany & 1670 & 21.6 & 16.3 to 28.0 \\
\hline \multicolumn{4}{|l|}{ Education } \\
\hline Low & 1953 & 45.5 & 42.9 to 48.2 \\
\hline Middle/High & 3118 & 54.5 & 51.8 to 57.1 \\
\hline Missing & 33 & & \\
\hline \multicolumn{4}{|l|}{ Living alone } \\
\hline Yes & 798 & 16.4 & 14.9 to 17.9 \\
\hline No & 4220 & 83.6 & 82.1 to 85.1 \\
\hline Missing & 86 & & \\
\hline \multicolumn{4}{|l|}{ Obesity (BMI $\left.\geq 30 \mathrm{~kg} / \mathrm{m}^{2}\right)$} \\
\hline Yes & 1412 & 28.3 & 26.6 to 30.2 \\
\hline No & 3656 & 71.7 & 69.8 to 73.4 \\
\hline Missing & 36 & & \\
\hline \multicolumn{4}{|l|}{ Currently smoking } \\
\hline Yes & 1085 & 24.0 & 22.2 to 25.9 \\
\hline No & 3989 & 76.0 & 74.1 to 77.8 \\
\hline Missing & 30 & & \\
\hline \multicolumn{4}{|l|}{ Sports activity } \\
\hline No sports & 1683 & 36.3 & 34.4 to 38.2 \\
\hline Any sports & 3260 & 63.7 & 61.8 to 65.6 \\
\hline Missing & 161 & & \\
\hline \multicolumn{4}{|l|}{ Alcohol use } \\
\hline No alcohol use & 618 & 13.9 & 12.5 to 15.4 \\
\hline Moderate drinking & 3474 & 68.8 & 67.0 to 70.4 \\
\hline Risky drinking & 937 & 17.3 & 16.1 to 18.7 \\
\hline Missing & 75 & & \\
\hline
\end{tabular}

Continued
Table 1 Continued

\begin{tabular}{|c|c|c|c|}
\hline & $\mathbf{N}$ & $\% *$ & $95 \% \mathrm{Cl}^{*}$ \\
\hline \multicolumn{4}{|c|}{ Parental history of diabetes } \\
\hline Yes & 1567 & 33.1 & 31.3 to 34.8 \\
\hline No & 3132 & 66.9 & 65.2 to 68.7 \\
\hline Missing & 405 & & \\
\hline \multicolumn{4}{|c|}{ Depressive symptoms (PHQ-9) } \\
\hline Yes (PHQ-9 >10) & 313 & 7.0 & 6.1 to 8.1 \\
\hline No $(P H Q-9<10)$ & 4482 & 93.0 & 91.9 to 93.9 \\
\hline Missing & 309 & & \\
\hline \multicolumn{4}{|l|}{ Hyperlipidemia } \\
\hline Yes & 1923 & 35.8 & 33.9 to 37.8 \\
\hline No & 3152 & 64.2 & 62.2 to 66.1 \\
\hline Missing & 29 & & \\
\hline \multicolumn{4}{|l|}{ Hypertension } \\
\hline Yes & 2481 & 44.8 & 43.0 to 46.7 \\
\hline No & 2614 & 55.2 & 53.3 to 57.0 \\
\hline Missing & 9 & & \\
\hline \multicolumn{4}{|c|}{ Visiting a doctor within past year } \\
\hline Yes & 4634 & 90.7 & 89.6 to 91.7 \\
\hline No & 415 & 9.3 & 8.3 to 10.4 \\
\hline Missing & 55 & & \\
\hline
\end{tabular}

Hyperlipidemia: defined as total cholesterol $\geq 6.2 \mathrm{mmol} / \mathrm{L}$ or currently using lipids-lowering drugs for the treatment of physician-diagnosed hyperlipidemia. Hypertension: defined as systolic blood pressure $\geq 140 \mathrm{~mm} \mathrm{Hg}$ (18.7 kPa) or diastolic blood pressure $\geq 90 \mathrm{~mm} \mathrm{Hg}(12.0 \mathrm{kPa})$ or currently using antihypertensive drugs for the treatment of physician-diagnosed hypertension.

*Weighted to the population of 31 December 2010.

BMI, body mass index; PHQ-9, 9-item depression module of the Patient Health Questionnaire.

$60 \%$ lived in middle or large cities. More than $50 \%$ had an intermediate or higher level of education and considerable proportions of the population had behavioral cardiometabolic risk factors, including nearly a fourth of current smokers, more than a third without any regular sports activity and $17 \%$ with risky alcohol consumption. Furthermore, $28 \%$ of people had obesity, more than a third of the population had hyperlipidemia and $45 \%$ had hypertension. The overall prevalence of current depressive symptoms amounted to $7 \%$. Nearly $91 \%$ of the study population reported to have seen a doctor within the past 12 months (table 1 ).

As shown in online supplemental annex table 1A, the distribution of study variables varied by glycemic status, with a higher mean age and a markedly higher prevalence of low education, physical inactivity, obesity, hypertension, hyperlipidemia and family history of diabetes among adults with diagnosed and undiagnosed T2D compared with normoglycemic persons. Persons with diagnosed T2D showed a lower prevalence of current smoking, and higher prevalence of current depressive symptoms 
than persons with undiagnosed T2D. The distribution of alcohol consumption by glycemic status differed with regard to a higher prevalence of persons reporting no alcohol consumption among adults with diagnosed T2D and a lower prevalence of risky drinking in association with diagnosed or undiagnosed T2D compared with normoglycemia. However, absolute numbers were small as reflected by wide $95 \%$ CIs. Compared with adults with normoglycemia, the prevalence of adults who had seen a doctor within the past year was higher among persons with diagnosed T2D, while the opposite was true for persons with undiagnosed T2D (online supplemental annex table 1A).

Results of multivariable regression analyses including four different models are summarized in table 2. In the final model, common factors associated with undiagnosed and diagnosed T2D versus normoglycemia included male sex, older age, obesity, parental history of diabetes and hypertension. Variables associated with undiagnosed T2D but not diagnosed T2D included living alone, and not seeing a doctor within the past year, while depressive symptoms and less risky drinking were factors associated with diagnosed T2D but not of undiagnosed T2D in comparison to normoglycemia (table 2). Lower education was significantly associated with undiagnosed as well as diagnosed T2D in model 1. Notably, residing in the western part of Germany was associated with undiagnosed T2D with an OR of 2.29 (95\% CI 0.93 to 5.61), although not reaching statistical significance.

In the final model, factors associated with undiagnosed versus diagnosed T2D included male sex, younger age, residing in the western part of Germany, not living with a partner and not visiting a doctor within the past (table 3).

No interactions were found between predictor variables and sex (data not shown). Results largely persisted in complete case analysis (online supplemental appendix table 2A).

\section{DISCUSSION}

In a nationally representative sample of communitydwelling adults aged 40-79 years in Germany, we found that people with undiagnosed T2D shared a number of known diabetes risk factors with people with diagnosed T2D including male sex, older age, obesity, history of hypertension and family history of diabetes. Variables independently associated with undiagnosed T2D but not diagnosed T2D in comparison with normoglycemia included living alone and not seeing a doctor within the past year. Compared with people with diagnosed T2D, people with undiagnosed T2D were further younger, more likely to be male sex and to reside in the western part of Germany.

\section{Factors associated with undiagnosed T2D}

Factors associated with undiagnosed T2D depend on the definition of undiagnosed T2D (by HbAlc, oral glucose tolerance test or fasting glucose, alone or combined), ${ }^{37}$ the chosen reference groups (normoglycemia or diagnosed T2D) and covariables as well as the composition of the study populations. People with undiagnosed T2D usually show little clinical symptoms and thus remain undetected. Generally, they are younger and healthier with less diabetes-related comorbidities compared with people with diagnosed T2D as they are usually at an earlier stage of diabetes. Nevertheless, undiagnosed and diagnosed T2D are not two different diseases, they rather reflect different stages of diabetes sharing the same pathophysiological pathway. Established risk factors of diabetes such as older age, male sex, parental history of diabetes, obesity and hypertension were consistently found here in the present study and previously both for diagnosed and undiagnosed diabetes. ${ }^{15} 181938$ Furthermore, we did not find any difference in terms of some 'classical' cardiometabolic risk factors of diabetes such as obesity, health behaviors, hypertension and hyperlipidemia by comparison between undiagnosed and diagnosed T2D after adjusting for sociodemographics. As previously reported, depressive symptoms were associated with diagnosed but not with undiagnosed T2D in our national health survey dataset. ${ }^{33}$ Overall, $>90 \%$ of the population in Germany see a doctor in office practice at least once a year. The present study showed that this does not apply to people with undiagnosed T2D who were significantly less likely to visit a doctor compared with people either with diagnosed T2D or with normoglycemia. Similar results were previously reported from Denmark $^{19}$ and the USA. ${ }^{14}$ The question then is what characterizes persons with lower healthcare utilization. Living alone was an independent correlate of undiagnosed T2D in the present study and in some,${ }^{28}$ although not all previous studies. ${ }^{19}$ Compared with persons who live with a partner, persons living alone may be more prone to develop diabetes due to lower social support and a higher probability of unfavorable health-related behaviors. ${ }^{39}$ A non-linear relationship between alcohol consumption and risk of diabetes was reported previously with moderate alcohol consumption being associated with lowest T2D risk. ${ }^{40}$ As the harm of heavy alcohol consumption on health is well recognized, people with diagnosed T2D may have been advised to change lifestyle such as doing more sports and not drinking too much or even withdrawing from alcohol drinking, leading to less risky drinking found among people with diagnosed T2D but not undiagnosed T2D versus normoglycemia. According to the guidelines for the management of T2D in Germany, people with diagnosed T2D should visit a doctor regularly for glycemic control, eye and foot exam, etc to prevent diabetes-related complications. It is thus no wonder that they visit a doctor more often than people with undiagnosed T2D within the past year.

Few previous studies have investigated factors associated with undiagnosed T2D versus diagnosed T2D in western populations. ${ }^{14} 2{ }^{38} 41$ Leahy et al examined correlates of undiagnosed versus diagnosed T2D among Irish men and women aged 50 years and over in primary 


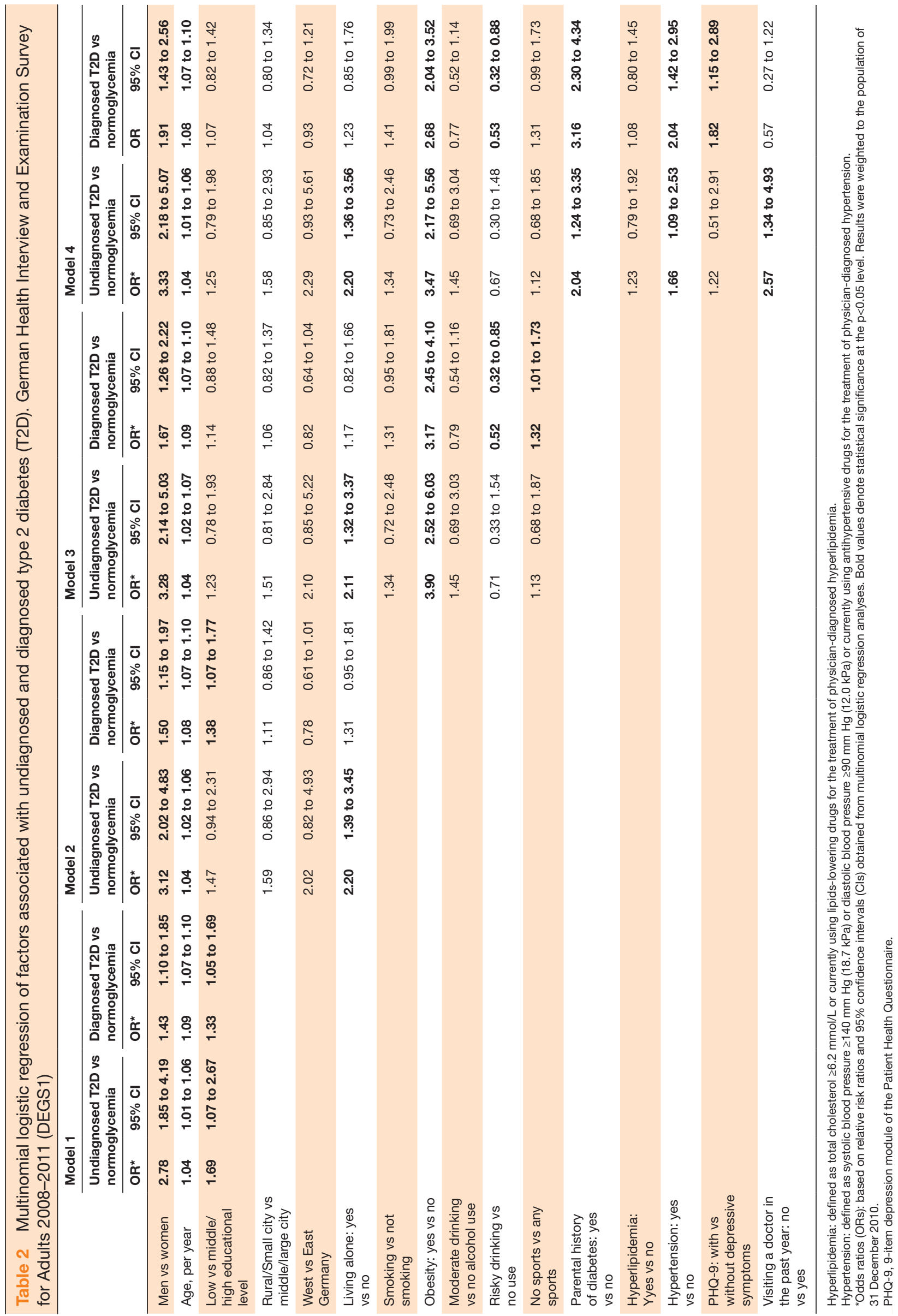


Table 3 Multinomial logistic regression of factors associated with undiagnosed vs diagnosed type 2 diabetes (T2D). German Health Interview and Examination Survey for Adults 2008-2011 (DEGS1)

\begin{tabular}{|c|c|c|c|}
\hline & \multicolumn{2}{|c|}{ Undiagnosed T2D vs diagnosed T2D } & \multirow[b]{2}{*}{$P$ value } \\
\hline & OR $^{\star}$ & $95 \% \mathrm{Cl}$ & \\
\hline \multicolumn{4}{|l|}{ Sex } \\
\hline Age, per year & 0.96 & 0.93 to 0.99 & 0.003 \\
\hline \multicolumn{4}{|l|}{ Community size } \\
\hline \multicolumn{4}{|l|}{ Region } \\
\hline West vs East Germany & 2.46 & 1.06 to 5.70 & 0.036 \\
\hline \multicolumn{4}{|l|}{ Education } \\
\hline Primary vs middle/high & 1.16 & 0.69 to 1.96 & 0.572 \\
\hline \multicolumn{4}{|l|}{ Living alone } \\
\hline Yes vs no & 1.30 & 0.76 to 2.21 & 0.340 \\
\hline \multicolumn{4}{|l|}{ Currently smoking } \\
\hline Smoking vs not smoking & 0.95 & 0.49 to 1.87 & 0.892 \\
\hline \multicolumn{4}{|l|}{ Alcohol use } \\
\hline Moderate drinking vs no use & 1.89 & 0.90 to 3.97 & 0.092 \\
\hline Risky drinking vs no use & 1.26 & 0.54 to 2.95 & 0.597 \\
\hline \multicolumn{4}{|l|}{ Sports activity } \\
\hline No sports vs any sports & 0.86 & 0.49 to 1.52 & 0.598 \\
\hline \multicolumn{4}{|l|}{ Parental history of diabetes } \\
\hline Yes vs no & 0.81 & 0.48 to 1.39 & 0.448 \\
\hline \multicolumn{4}{|l|}{ Visiting a doctor within the past year } \\
\hline No vs yes & 4.50 & 1.85 to 10.97 & 0.001 \\
\hline
\end{tabular}

Hyperlipidemia: defined as total cholesterol $\geq 6.2 \mathrm{mmol} / \mathrm{L}$ or currently using lipids-lowering drugs for the treatment of physician-diagnosed hyperlipidemia.

Hypertension: defined as systolic blood pressure $\geq 140 \mathrm{~mm} \mathrm{Hg}(18.7 \mathrm{kPa})$ or diastolic blood pressure $\geq 90 \mathrm{~mm} \mathrm{Hg}(12.0 \mathrm{kPa})$ or currently using antihypertensive drugs for the treatment of physician-diagnosed hypertension.

${ }^{*}$ Odds ratios (ORs) based on relative risk ratios and $95 \%$ confidence intervals (Cls) obtained from multinomial logistic regression. Bold values denote statistical significance at the $p<0.05$ level. Results were weighted to the population of 31 December 2010.

BMI, body mass index; PHQ-9, 9-item depression module of the Patient Health Questionnaire.

care. In agreement with our results, this previous study found that both groups did not differ with regard to major diabetes-related risk factors including hypertension, hyperlipidemia, obesity, smoking, physical activity or low education. ${ }^{20}$ However, unlike the present study this previous study did not find differences regarding age, male sex, marital status and general practitioner visits in the past 12 months despite a similar study design and a similar definition for undiagnosed T2D. ${ }^{20}$ Another primary care study among middle-aged Irish adults 50-69 years found that adults with undiagnosed versus diagnosed T2D were more likely to have higher BMI and physical inactivity and less likely to have a family history of T2D diabetes. ${ }^{38}$ Similar results regarding obesity were reported based on a comparison of adults with undiagnosed and diagnosed diabetes in the study using data from the 1988-1994 US National Health and Nutrition Examination Survey. ${ }^{41}$ This previous analysis did not find 
group differences either regarding age, male sex, education or marital status, which were confirmed in a study by using 2007-2012 US National Health and Nutrition Survey data. ${ }^{14}$ In our study, lower education was significantly associated with undiagnosed as well as diagnosed T2D in model 1. However, the association was explained by cohabitation status among persons with undiagnosed T2D and by obesity among persons with diagnosed T2D. Similar to our results, having no access to healthcare increased the odds of undiagnosed versus diagnosed diabetes both for white and Hispanic adults. ${ }^{14}$ In addition, we found persons with undiagnosed T2D were more likely to reside in the western part of Germany than in eastern part of Germany. This is in line with our previous findings that prevalence of undiagnosed diabetes in the eastern part of Germany decreased due to increased screening activities, which leads to a higher prevalence of undiagnosed diabetes being found in the western part of Germany than in the eastern part of Germany. ${ }^{13}$ Together these results differences in factors associated with undiagnosed diabetes between studies suggest country-specific screening strategies targeting on vulnerable population subgroups for undiagnosed T2D be needed.

\section{Strengths and limitations}

The main strength of this study is that we used data from a nationally representative sample of community-dwelling adults in Germany. A wide variety of factors potentially associated with undiagnosed diabetes could be examined in regression models. However, there are several limitations. First, a selection bias cannot be ruled out. People aged 80 years and older, hospitalized and institutionalized (eg, those in nursing-homes) were not included in the national health survey. These people are expected to be at a high risk of diagnosed and undiagnosed T2D due to multiple morbidities at an advanced age. Second, some misclassification biases cannot be excluded. The low prevalence of T1D and low proportion among adults with diabetes in DEGS1 ${ }^{30}$ suggested that people with T1D may have not been excluded completely. Although undiagnosed T1D is theoretically possible, as the onset of T1D can be abrupt, we treated all people with defined undiagnosed diabetes as those having undiagnosed T2D. In addition, the definition of undiagnosed T2D relied on only one single HbA1c test as data of fasting plasma glucose and 2-hour glucose tolerance test are unavailable in DEGS1. HbA1c, alone ${ }^{141517-2038}$ or in combination with fasting glucose and oral glucose tolerance test, ${ }^{15} 16$ is widely used for diagnosing diabetes in many epidemiological studies due to its practicality and convenience. Previous studies suggest that HbAlc-based methods may underestimate prevalence of undiagnosed diabetes. ${ }^{42-44}$ Given discrepancy and concerns for the definitions of undiagnosed diabetes by different criteria in epidemiological studies, ${ }^{3744}$ studies may be required to investigate if factors associated with undiagnosed diabetes vary with different criteria for diagnosing diabetes in epidemiological studies. Third, in the regression models we have considered potential factors as best as possible. Other factors that have an influence on the prevalence, diagnosis and prevention of diabetes may have not been considered. For example, there's evidence suggesting that prevalence of undiagnosed diabetes was higher among Hispanic than among white American adults and factors associated with undiagnosed diabetes differed between the two groups. ${ }^{14}$ It was not possible to consider immigration background in the present analysis, although this factor is likely to be linked with language barriers affecting access to medical care. As of $2010,18.3 \%$ of the population in Germany had an immigration background. ${ }^{45}$ However, although efforts were taken to include people with immigration background, in particular first-generation immigrants were well under-represented in DEGS1. ${ }^{46}$ This initiated improving concepts and methods for inclusion of the growing and increasingly heterogeneous group of the population in Germany with immigration background into national health monitoring activities. ${ }^{47}$ Furthermore, little is known about the awareness of diabetes risk and the willingness to change lifestyle to reduce already recognized modifiable risk factors of T2D. Both play a critical role in the diagnosis and prevention of T2D. Fourth, although multiple imputation methods result in valid statistical inferences, our results-particularly for those factors with a 95\% CI near 1 should be interpreted with caution given the high proportion of study subjects with missing observations in some variables. However, differences in results between imputed data and complete case data were rather low.

\section{Implications for public health research and practice}

Our results emphasize the importance of understanding factors that are associated with undiagnosed diabetes, even in countries with universal access to healthcare. Factors may vary according to the definition of unknown diabetes and specific context factors may also change over time. Thus, monitoring of potential drivers of undiagnosed diabetes is necessary at the national and regional level. Most importantly, future research needs to include particularly vulnerable groups of the population at high risk of diabetes and limited access to the healthcare system, such as persons with immigration background and language barriers. In Germany, results of the present study will inform the national education and communication strategy on diabetes mellitus, which is currently developed by the German Federal Center for Health Education.

\section{CONCLUSIONS}

In the present study, we identified a number of characteristics that were associated with undiagnosed T2D among adults in Germany. Apart from major known risk factors of diabetes, younger age, male sex, residing in the western part of Germany, living alone and not regularly seeing a doctor were factors associated with undiagnosed diabetes 
versus diagnosed diabetes. These results deserve further investigation as they are relevant to improve the detection of undiagnosed diabetes and targeted T2D risk communication as part of the national education and communication strategy on diabetes mellitus in Germany, which is currently developed by the German Federal Center for Health Education. Further studies should also consider factors such as barriers to awareness of diabetes risks and the willingness to change lifestyles, some of which may be related to personal factors and others to living conditions and the healthcare system.

Contributors YD assisted to conceptualize the study, performed the statistical analyses and drafted the manuscript. JB provided statistical consulting, reviewed the manuscript and contributed to the discussion. RP and AT reviewed the manuscript and contributed to the discussion. $\mathrm{CH}$ assisted to conceptualize the study, reviewed the manuscript and contributed to the discussion. CS-N conceptualized and supervised the study and contributed to the discussion and to the writing of the manuscript. CS-N is the guarantor who takes full responsibility for the work as a whole.

Funding This work was supported by a research grant from the German Federal Ministry of Health to develop a diabetes surveillance system in Germany (Grant Number: GE 201503 23, GE 201903 05). The conduction of national health surveys in Germany is funded by the Federal Ministry of Health as part of the continuous national health monitoring.

Competing interests None declared.

Patient consent for publication Not required.

Ethics approval DEGS1 was approved by the Federal and State Commissioners for Data Protection and the Charité-Universitätsmedizin Berlin ethics committee (№. EA2/047/08). Participants provided a written informed consent prior to interviews and examinations.

Provenance and peer review Not commissioned; externally peer reviewed.

Data availability statement Data are available on reasonable request. For the DEGS survey, additional data are available for research collaborations as described in the DEGS study protocol (http://www.biomedcentral.com/1471-2458/12/730).

Supplemental material This content has been supplied by the author(s). It has not been vetted by BMJ Publishing Group Limited (BMJ) and may not have been peer-reviewed. Any opinions or recommendations discussed are solely those of the author(s) and are not endorsed by BMJ. BMJ disclaims all liability and responsibility arising from any reliance placed on the content. Where the content includes any translated material, BMJ does not warrant the accuracy and reliability of the translations (including but not limited to local regulations, clinical guidelines, terminology, drug names and drug dosages), and is not responsible for any error and/or omissions arising from translation and adaptation or otherwise.

Open access This is an open access article distributed in accordance with the Creative Commons Attribution Non Commercial (CC BY-NC 4.0) license, which permits others to distribute, remix, adapt, build upon this work non-commercially, and license their derivative works on different terms, provided the original work is properly cited, appropriate credit is given, any changes made indicated, and the use is non-commercial. See: http://creativecommons.org/licenses/by-nc/4.0/.

\section{ORCID iDs}

Yong Du http://orcid.org/0000-0001-8309-9293

Jens Baumert http://orcid.org/0000-0003-1399-6874

Andrea Teti https://orcid.org/0000-0002-2112-4112

Christin Heidemann http://orcid.org/0000-0002-9413-2148

\section{REFERENCES}

1 Harris MI, Eastman RC. Early detection of undiagnosed diabetes mellitus: a US perspective. Diabetes Metab Res Rev 2000;16:230-6.

2 Spijkerman AMW, Dekker JM, Nijpels G, et al. Microvascular complications at time of diagnosis of type 2 diabetes are similar among diabetic patients detected by targeted screening and patients newly diagnosed in general practice: the hoorn screening study. Diabetes Care 2003;26:2604-8.
3 Ponto KA, Koenig J, Peto T, et al. Prevalence of diabetic retinopathy in screening-detected diabetes mellitus: results from the Gutenberg health study (GHS). Diabetologia 2016;59:1913-9.

4 Fornengo P, Bosio A, Epifani G, et al. Prevalence of silent myocardial ischaemia in new-onset middle-aged type 2 diabetic patients without other cardiovascular risk factors. Diabet Med 2006;23:775-9.

5 Paprott R, Schaffrath Rosario A, Busch MA, et al. Association between hemoglobin A1c and all-cause mortality: results of the mortality follow-up of the German National health interview and examination survey 1998. Diabetes Care 2015;38:249-56.

6 Röckl S, Brinks R, Baumert J, et al. All-Cause mortality in adults with and without type 2 diabetes: findings from the National health monitoring in Germany. BMJ Open Diabetes Res Care 2017:5:e000451.

7 Simmons RK, Griffin SJ, Lauritzen T, et al. Effect of screening for type 2 diabetes on risk of cardiovascular disease and mortality: a controlled trial among 139,075 individuals diagnosed with diabetes in Denmark between 2001 and 2009. Diabetologia 2017;60:2192-9.

8 Feldman AL, Griffin SJ, Fhärm E, et al. Screening for type 2 diabetes: do screen-detected cases fare better? Diabetologia 2017;60:2200-9.

9 Simmons RK, Griffin SJ, Witte DR, et al. Effect of population screening for type 2 diabetes and cardiovascular risk factors on mortality rate and cardiovascular events: a controlled trial among 1,912,392 Danish adults. Diabetologia 2017;60:2183-91.

10 Simmons D, Zgibor JC. Should we screen for type 2 diabetes among asymptomatic individuals? Yes. Diabetologia 2017;60:2148-52.

11 Beagley J, Guariguata L, Weil C, et al. Global estimates of undiagnosed diabetes in adults. Diabetes Res Clin Pract 2014;103:150-60.

12 Saeedi P, Petersohn I, Salpea P, et al. Global and regional diabetes prevalence estimates for 2019 and projections for 2030 and 2045: Results from the International Diabetes Federation Diabetes Atlas, $9^{\text {th }}$ edition. Diabetes Res Clin Pract 2019;157:107843.

13 Heidemann C, Du Y, Paprott R, et al. Temporal changes in the prevalence of diagnosed diabetes, undiagnosed diabetes and prediabetes: findings from the German health interview and examination surveys in 1997-1999 and 2008-2011. Diabet Med 2016;33:1406-14.

14 Russell E, Oh KM, Zhao X. Undiagnosed diabetes among Hispanic and white adults with elevated haemoglobin $A_{1 c}$ levels. Diabetes Metab Res Rev 2019;35:e3153.

15 Zhang N, Yang X, Zhu X, et al. Type 2 diabetes mellitus unawareness, prevalence, trends and risk factors: National health and nutrition examination survey (NHANES) 1999-2010. J Int Med Res 2017;45:594-609.

16 Casagrande SS, Menke A, Aviles-Santa L, et al. Factors associated with undiagnosed diabetes among adults with diabetes: results from the Hispanic community health Study/Study of Latinos (HCHS/SOL). Diabetes Res Clin Pract 2018;146:258-66.

17 Xiao M, O'Neill C, O'Neill C. Detection and management of diabetes in England: results from the health survey for England. Diabetes Ther 2017;8:1163-74.

18 Moody A, Cowley G, Ng Fat L, et al. Social inequalities in prevalence of diagnosed and undiagnosed diabetes and impaired glucose regulation in participants in the health surveys for England series. BMJ Open 2016;6:e010155.

19 Heltberg A, Andersen JS, Sandholdt H, et al. Predictors of undiagnosed prevalent type 2 diabetes - The Danish General Suburban Population Study. Prim Care Diabetes 2018;12:13-22.

20 Leahy S, O' Halloran AM, O' Leary N, et al. Prevalence and correlates of diagnosed and undiagnosed type 2 diabetes mellitus and pre-diabetes in older adults: findings from the Irish longitudinal study on ageing (TILDA). Diabetes Res Clin Pract 2015;110:241-9.

21 O Connor JM, Millar SR, Buckley CM, et al. The prevalence and determinants of undiagnosed and diagnosed type 2 diabetes in middle-aged Irish adults. PLoS One 2013;8:e80504.

22 Lee Y-H, Armstrong EJ, Kim G, et al. Undiagnosed diabetes is prevalent in younger adults and associated with a higher risk cardiometabolic profile compared to diagnosed diabetes. Am Heart $J$ 2015;170:e2:760-9.

23 Salas A, Acosta D, Ferri CP, et al. The prevalence, correlates, detection and control of diabetes among older people in low and middle income countries. A 10/66 dementia research Group population-based survey. PLoS One 2016;11:e0149616.

24 Bantie GM, Wondaye AA, Arike EB, et al. Prevalence of undiagnosed diabetes mellitus and associated factors among adult residents of Bahir Dar City, Northwest Ethiopia: a community-based crosssectional study. BMJ Open 2019;9:e030158.

25 Rahim FF, Abdulrahman SA, Kader Maideen SF, et al. Prevalence and factors associated with prediabetes and diabetes in fishing 
communities in penang, Malaysia: a cross-sectional study. PLoS One 2020;15:e0228570.

26 Hallit S, Saade S, Zeidan RK, et al. Factors associated with undiagnosed type II diabetes mellitus, undiagnosed impaired fasting glucose and these patients' quality of life in Lebanon. $J$ Public Health 2020;42:550-60.

27 Echouffo-Tcheugui JB, Dzudie A, Epacka ME, et al. Prevalence and determinants of undiagnosed diabetes in an urban sub-Saharan African population. Prim Care Diabetes 2012;6:229-34.

28 Heianza Y, Arase Y, Kodama S, et al. Association of living alone with the presence of undiagnosed diabetes in Japanese men: the role of modifiable risk factors for diabetes: Toranomon Hospital health management center study 13 (topics 13). Diabet Med 2013;30:1355-9.

29 Scheidt-Nave C, Kamtsiuris P, Gößwald A, et al. German health interview and examination survey for adults (DEGS) - design, objectives and implementation of the first data collection wave. BMC Public Health 2012;12:730.

30 Heidemann C, Du Y, Schubert I, et al. [Prevalence and temporal trend of known diabetes mellitus: results of the German Health Interview and Examination Survey for Adults (DEGS1)]. Bundesgesundheitsblatt Gesundheitsforschung Gesundheitsschutz 2013;56:668-77.

31 Brauns H, Scherer S SS. The CASMIN educational classification in international comparative research. In: Hoffmeyer-Zlotnik JHP WC, ed. Advances in cross-national comparison: an European working book for demographic and socio-economic variables. New Youk: Kluwer, 2003: 221-44.

32 Du Y, Heidemann C, Schaffrath Rosario A, et al. Changes in diabetes care indicators: findings from German National health interview and examination surveys 1997-1999 and 2008-2011. BMJ Open Diabetes Res Care 2015;3:e000135.

33 Weikert B, Buttery AK, Heidemann C, et al. Glycaemic status and depressive symptoms among adults in Germany: results from the German health interview and examination survey for adults (DEGS1). Diabet Med 2018;35:1552-61.

34 Neuhauser H, Thamm M, Ellert U. [Blood pressure in Germany 2008-2011: results of the German Health Interview and Examination Survey for Adults (DEGS1)]. Bundesgesundheitsblatt Gesundheitsforschung Gesundheitsschutz 2013;56:795-801.
35 Gould W. Interpreting logistic regression in all its forms. Stata Technical Bulletin 2000;9:19-29.

36 Rubin D. Multiple imputation for nonresponse in surveys. John Wiley \& Sons, Inc, 1987

37 Geiss LS, Bullard KM, Brinks R, et al. Considerations in epidemiologic definitions of undiagnosed diabetes. Diabetes Care 2018;41:1835-8.

38 O Connor JM, Millar SR, Buckley CM, et al. The prevalence and determinants of undiagnosed and diagnosed type 2 diabetes in middle-aged Irish adults. PLoS One 2013;8:e80504.

39 Cornelis MC, Chiuve SE, Glymour MM, et al. Bachelors, divorcees, and widowers: does marriage protect men from type 2 diabetes? PLoS One 2014;9:e106720

40 Holst C, Becker U, Jørgensen ME, et al. Alcohol drinking patterns and risk of diabetes: a cohort study of 70,551 men and women from the general Danish population. Diabetologia 2017;60:1941-50.

41 Wilder RP, Majumdar SR, Klarenbach SW, et al. Socio-Economic status and undiagnosed diabetes. Diabetes Res Clin Pract 2005;70:26-30.

42 Karnchanasorn R, Huang J, Ou H-Y, et al. Comparison of the current diagnostic criterion of $\mathrm{HbA} 1 \mathrm{c}$ with fasting and 2-hour plasma glucose concentration. J Diabetes Res 2016;2016:1-11.

43 Cowie CC, Rust KF, Byrd-Holt DD, et al. Prevalence of diabetes and high risk for diabetes using A1c criteria in the U.S. population in 1988-2006. Diabetes Care 2010;33:562-8.

44 NCD Risk Factor Collaboration (NCD-RisC). Effects of diabetes definition on global surveillance of diabetes prevalence and diagnosis: a pooled analysis of 96 population-based studies with 331,288 participants. Lancet Diabetes Endocrinol 2015;3:624-37.

45 Statistisches Bundesamt (Destatis). Bevölkerung MIT Migrationshintergrund - Ergebnisse des Mikrozensus 2010 hochgerechnet auf basis des Zensus 2011, 2017.

46 Saß A-C, Grüne B, Brettschneider A-K, et al. Beteiligung von Menschen MIT Migrationshintergrund an Gesundheitssurveys des Robert Koch-Instituts: Robert Koch-Institut, Epidemiologie und Gesundheitsberichterstattung, 2015.

47 Schumann M, Kajikhina K, Polizzi A, et al. Concepts for migrationsensitive health monitoring. Journal of Health Monitoring 2019;4:49-65. 